\title{
Ocular manifestations of onchocerciasis in a rain forest area of West Africa
}

Dana Center for Preventive Ophthalmology, Wilmer Institute, Johns Hopkins University, Baltimore, Maryland, USA H S Newland R P Murphy H R Taylor

Division of Georgraphic Medicine, University of Alabama at Birmingham, Birmingham, Alabama, USA

A T White

B M Greene

Correspondence to: $H S$ Newland, MD, Flinders Medical Centre, Bedford Park, South Australia 5042, South Aus
Australia.

Accepted for publication 16 August 1990

\author{
Henry S Newland, Albert T White, Bruce M Greene, Robert P Murphy, Hugh R Taylor
}

\begin{abstract}
The epidemiology and natural history of onchocerciasis and its ocular complications in rain forest areas are poorly understood. The present study was conducted on a rubber plantation-in a hyperendemic area in the rain forest of Liberia, West Africa, where 800 persons were examined. The prevalence of infection was $84 \%$ overall $29 \%$ had intraocular microfilariae, and $2.4 \%$ were blind in one or both eyes. Onchocerciasis was the cause of all binocular blindness and one-third of all visual impairment. Over half of the visual impairment caused by onchocerciasis was due to posterior segment diseases. Chorioretinal changes were present in $75 \%$ of people, and included intraretinal pigment clumping in $52 \%$ and retinal pigment epithelium atrophy in $32 \%$. Atrophy of the retinal pigment epithelium was associated with increasing age and severity of infection. Intraretinal pigment was strongly associated with anterior uveitis. There was a strong correlation between uveitis and the inflammatory chorioretinal sequelae: retinitis, intraretinal pigment, subretinal fibrosis, and optic neuropathy. These findings indicate that considerable visual impairment associated with rain forest onchocerciasis is common and is due largely to chorioretinal disease.
\end{abstract}

Onchocerciasis is a major public health problem in equatorial West Africa. ${ }^{1}$ Furthermore, mortality in blind adults is, on average, three to four times greater than of people of the same age who can see. ${ }^{2}$ Although much has been learned about the systemic manifestations of the disease and the ocular changes in the anterior segment, especially in savanna areas, ${ }^{34}$ relatively little is known about the epidemiology and natural history of the ocular complications in rain forest areas of West Africa.

While onchocerciasis has been known to exist in Liberia since $1926,{ }^{5}$ the importance of its ocular sequelae was not initially appreciated. A small study in $1955^{6}$ found little evidence for severe ocular disease and reported a prevalence of infection of $40 \%$, with $10 \%$ of patients having ocular involvement. Another report in 1958 found a prevalence of infection of $69 \%$, but no cases of blindness or obvious lesions due to onchocerciasis were found despite slit-lamp examination. ${ }^{7}$ Another study reported that $49 \%$ of adults infected with Onchocerca volvulus had microfilariae in the lateral canthus of the eye, an indicator of ocular involvement. ${ }^{8}$ Subsequent studies, however, have indicated that onchocerciasis is an important blinding disease in Liberia. In 1973, Frentzel-Beyme found significant ocular onchocerciasis and a blindness rate of
$1.2 \%$ in the Bong Range. ${ }^{9}$ This was double the rate found in areas of Liberia free of onchocerciasis. In 1978 Connor and coworkers reported chorioretinitis in $22 \%$ and a blindness prevalence of approximately $1 \%$ in northern Liberia. ${ }^{10}$ Chorioretinitis has also been reported in a high proportion of patients studied in clinical trials in Liberia. ${ }^{11}$

We undertook a more detailed ocular survey of a population in a hyperendemic area of Liberia to provide further information on the epidemiology and natural history of anterior and posterior segment ocular disease in Liberia and on risk factors associated with those chorioretinal changes.

\section{Materials and methods}

\section{CENSUS AND SAMPLING}

Employees and their dependants on the Liberian Agricultural Company (LAC) Rubber Plantation in Grand Bassa County, Liberia, were chosen as the study population. A house-by-house census of 1997 people in 18 camps was taken, and the offer of participation in a clinical trial was made. A census card recording name, house, camp, age, sex, tribe, and occupation was completed for each person aged 12 years or more. Participants generally, lived within walking distance of the examination clinic, though transport was available when needed.

\section{EXAMINATION PROCEDURE}

Uncorrected and corrected visual acuity was tested by illiterate $E$ chart at $6 \mathrm{~m}$. If either acuity was $<6 / 12$, it was assessed with a pinhole. The visual fields were tested with a clear dome Goodlite perimeter with fibre optic target. Fields were recorded as normal, $40-20^{\circ}, 20-10^{\circ},<10^{\circ}$ residual field, or absent.

Before anterior segment examination with a Topcon SL5D slit-lamp the patient was positioned in the head-down position for at least two minutes. Then the number of live microfilariae in the anterior chamber was counted (MfAC).

On the basis of presence and extent of flare and cells in the anterior chamber, uveitis was graded as absent, mild, moderate, or severe. The numbers and locations of live and dead microfilariae and punctate opacities in the cornea were recorded. Limbitis was diagnosed by the presence of limbal vessel dilatation, limbal oedema, or white globular opacities. The severity of limbitis was graded as absent, mild, moderate, or severe. Sclerosing keratitis was graded as absent, limbal haze, stroma opacified, or vascularised in the nasal or temporal meridian, 
with or without confluence inferiorly, or completely covering the pupil. Intraocular pressure was measured on all patients over 30 years old with a Goldmann applanation tonometer. The remainder of the anterior segment structures were examined by the slit-lamp, and any other abnormalities were recorded.

After pupil dilatation with $1 \%$ tropicamide and $10 \%$ phenylephrine, direct and indirect ophthalmoscopy was performed, and fundal abnormalities were recorded. Colour photographs were taken of the Diabetic Research Study fields $1,2,3$, and 8 (nasal to disc) with a Topcon FE fundus camera. ${ }^{12}$ Subsequently the photographs were evaluated in a masked fashion with patient identity obscured. The chorioretinal changes were graded according to the presence and extent of retinal pigment epithelium atrophy, intraretinal pigment clumping, shiny and white intraretinal deposits, retinitis, subretinal fibrosis, and optic neuropathy (neuritis or atrophy); any other abnormalities were also noted.

A medical history was taken, and it included a review of the dermatological, cardiovascular, nervous, and lymphatic systems. A thorough physical examination was also performed with particular reference to the general appearance, location of nodules, lymphadenopathy, dermatological findings, and weight.

Skin biopsies were taken bilaterally with a Holth-type corneoscleral punch from the scapulae, upper buttocks, and calves. These were individually weighed and placed in a flatbottom microtitre plate well containing $0.1 \mathrm{ml}$ of tissue culture medium (Roswell Park Memorial Institute: RPMI) with penicillin $(100 \mathrm{U} / \mathrm{ml})$ and streptomycin (100 $\mu \mathrm{g} / \mathrm{mg}$.) Microfilariae were counted after overnight incubation, and the density of infection was expressed as number per mg of skin (MfS).

\section{DATA ANALYSIS}

The analyses included: (1) simple frequency distribution for descriptive analysis; (2) Student's $t$ test for comparison between means; (3) $\chi^{2}$ or Fisher's exact test for comparison of proportions; (4) Pearson's correlation for the computation of bivariate correlation; and (5) multiple regression for computation of the adjusted correlation coefficient.

\section{Results}

\section{STUDY POPULATION}

A total of 800 persons aged 12 years or more voluntarily reported for detailed physical, parasitological, and ocular examination. The mean camp size was 111 , and the mean response rate was $40 \%$. The age and sex distribution of those who were examined was the same as that for the general population, and no obvious sources of selection bias were seen (Table 1).

PREVALENCE AND INTENSITY OF INFECTION

The overall prevalence of infection was $84 \cdot 3 \%$ (Table 2). The prevalence was uniformly high in all age groups and was similar for each sex. It was
Table 1. Age and sex distribution of census and study populations

\begin{tabular}{lccc}
\hline Age $($ Years $)$ & Male & Female & \multicolumn{1}{l}{ Total } \\
\hline \multicolumn{1}{l}{ Census Population } & & & \\
$12-19$ & $280(24 \cdot 5 \%)$ & $253(29 \cdot 6 \%)$ & $553(26 \cdot 7 \%)$ \\
$20-29$ & $337(29 \cdot 5)$ & $357(41 \cdot 8 \%)$ & $694(34 \cdot 8 \%)$ \\
$30-39$ & $281(24 \cdot 6 \%)$ & $185(21 \cdot 6 \%)$ & $466(23 \cdot 3 \%)$ \\
$40-49$ & $161(14 \cdot 1 \%)$ & $44(5 \cdot 1 \%)$ & $205(10 \cdot 2 \%)$ \\
$50+$ & $83(7 \cdot 3 \%)$ & $16(1 \cdot 9 \%)$ & $99(5 \cdot 0 \%)$ \\
Total & $1142(100 \%)$ & $855(100 \%)$ & $1997(100 \%)$ \\
Study population & $146(28 \cdot 6 \%)$ & $95(32 \cdot 9 \%)$ & $241(30 \cdot 1 \%)$ \\
$12-19$ & $139(27 \cdot 2 \%)$ & $96(33 \cdot 2 \%)$ & $235(29 \cdot 4 \%)$ \\
$20-29$ & $111(21 \cdot 7 \%)$ & $70(24 \cdot 2 \%)$ & $181(22 \cdot 6 \%)$ \\
$30-39$ & $84(16 \cdot 4 \%)$ & $20(6 \cdot 9 \%)$ & $104(13 \cdot 0 \%)$ \\
$40-49$ & $31(6 \cdot 1 \%)$ & $8(2 \cdot 8 \%)$ & $39(4 \cdot 9 \%)$ \\
$50+$ & $511(100 \%)$ & $289(100 \%)$ & $800(100 \%)$ \\
Total & & & \\
\hline
\end{tabular}

Table 2 Prevalence and density of infection by age, sex, and occupation

\begin{tabular}{lllll}
\hline Total & $\begin{array}{l}\text { Number } \\
\text { tested }\end{array}$ & $\begin{array}{l}\text { Density } \\
\text { positive }\end{array}$ & $\begin{array}{l}\text { Prevalence } \\
\text { MF/mg skin }\end{array}$ & $(\%)$ \\
\hline Total & $776^{\star}$ & 654 & $5 \cdot 3$ & $84 \cdot 3$ \\
Age & 229 & 184 & $4 \cdot 0$ & $80 \cdot 4$ \\
$12-19$ & 231 & 199 & $5 \cdot 1$ & $86 \cdot 2$ \\
$20-29$ & 175 & 145 & $5 \cdot 5$ & $82 \cdot 9$ \\
$30-39$ & 103 & 92 & $8 \cdot 1$ & $89 \cdot 3$ \\
$40-49$ & 38 & 34 & $8 \cdot 8$ & $89 \cdot 5$ \\
$50+$ & & & & \\
Sex & 449 & 424 & $6 \cdot 5$ & $85 \cdot 0$ \\
Male & 277 & 230 & $3 \cdot 5$ & $83 \cdot 0$ \\
Female & & 192 & $8 \cdot 6$ & $89 \cdot 3$ \\
Occupation & 215 & 192 & $4 \cdot 4$ & $86 \cdot 6$ \\
Tapper & 186 & 161 & 3.9 & $78 \cdot 7$ \\
Housewife & 221 & 174 & $5 \cdot 0$ & $82 \cdot 5$ \\
Student & 154 & 127 & & \\
Othert & & &
\end{tabular}

$\star$ Skin snips from 24 patients were mislaid. †other occupations included factory workers, drivers, teachers, and nurses.

Table 3 Proportion with monocular or binocular visual impairment by age, sex, and occupation

\begin{tabular}{llrl}
\hline $\begin{array}{l}\text { Total } \\
\text { each group }\end{array}$ & $\begin{array}{l}\text { Number } \\
793 \ddagger\end{array}$ & $\begin{array}{l}\text { Blind } \\
19(2 \cdot 4 \%)\end{array}$ & $\begin{array}{l}\text { Low Visiont } \\
10(1 \cdot 3 \%)\end{array}$ \\
\hline Age & & & \\
$12-19$ & 241 & $2(0 \cdot 8 \%)$ & $4(1 \cdot 7 \%)$ \\
$20-29$ & 233 & $6(2 \cdot 6 \%)$ & $2(0 \cdot 9 \%)$ \\
$30-39$ & 178 & $1(0 \cdot 6 \%)$ & $2(1 \cdot 1 \%)$ \\
$40+$ & 141 & $10(7 \cdot 1 \%)$ & $2(1 \cdot 4 \%)$ \\
Sex & 509 & $8(1 \cdot 6 \%)$ & $7(1 \cdot 4 \%)$ \\
Males & 284 & $11(3 \cdot 9 \%)$ & $3(1 \cdot 1 \%)$ \\
Females & & $4(1.9 \%)$ & $3(1 \cdot 4 \%)$ \\
$\begin{array}{l}\text { Occupation } \\
\text { Tapper }\end{array}$ & 215 & $15(2 \cdot 6 \%)$ & $7(1 \cdot 2 \%)$ \\
$\begin{array}{l}\text { Other } \\
\quad \text { Combined) }\end{array}$ & 578 & & \\
\hline
\end{tabular}

Blind: vision less than $3 / 60$ in one or both eyes. + Low vision: less than $6 / 18$ to $3 / 60$ in one or both eyes. $¥$ Seven subjects were unable to comprehend the visual acuity test.

significantly higher in those who worked as rubber tappers $(89.3 \%)$ than in those with any other occupation $(<0.02)$

Density of infection increased with age, and in males $(6.5$ microfilariae $/ \mathrm{mg})$ it was almost twice that in females ( 3.5 microfilariae/mg) (Table 2). Tappers were also the most heavily infected occupational group ( $8.6 \mathrm{microfilariae} / \mathrm{mg})$ with students having the lowest density $(3.9$ microfilariae/mg).

\section{BLINDNESS AND VISUAL IMPAIRMENT}

The rates of blindness and visual impairment increased with age, with the highest rates occurring in people over 40 (Table 3). There were fewer blind males $(1.6 \%)$ than blind females (3.9\%). Although there was less blindness among the tappers $(1.9 \%)$ than in other occupations $(2 \cdot 6 \%)$, more $(1 \cdot 4 \%)$ had low vision than did those with other occupations $(1 \cdot 2 \%)$. 
Table 4 Prevalence of monocular and binocular visual impairment by cause among study population

\begin{tabular}{|c|c|c|c|c|}
\hline \multirow[b]{2}{*}{ Cause } & \multicolumn{2}{|c|}{ Binocular (better eye) } & \multicolumn{2}{|l|}{ Monocular } \\
\hline & $\begin{array}{l}\text { Blind } \\
\text { Number (\%) }\end{array}$ & $\begin{array}{l}\text { Low visiont } \\
\text { Number (\%) }\end{array}$ & $\begin{array}{l}\text { Blind } \\
\text { Number (\%) }\end{array}$ & $\begin{array}{l}\text { Low vision } \\
\text { Number }(\%)\end{array}$ \\
\hline $\begin{array}{l}\text { Onchocerciasis } \\
\text { Glaucoma } \\
\text { Cataract } \\
\text { Toxoplasmosis } \\
\text { Trauma } \\
\text { Amblyopia } \\
\text { Refractive error } \\
\text { Other } \\
\text { Total }\end{array}$ & $\begin{array}{l}3(0.4) \\
0(0.0) \\
0(0.0) \\
0(0.0) \\
0(0.0) \\
0(0.0) \\
0(0.0) \\
0(0.0) \\
3(0.4)\end{array}$ & $\begin{array}{l}1(0 \cdot 1) \\
1(0 \cdot 1) \\
1(0 \cdot 1) \\
0(0 \cdot 0) \\
0(0 \cdot 0) \\
0(0 \cdot 0) \\
1(0 \cdot 1) \\
1(0 \cdot 1) \\
5(0.6)\end{array}$ & $\begin{array}{l}5(0 \cdot 6) \\
2(0 \cdot 3) \\
2(0 \cdot 3) \\
1(0 \cdot 1) \\
4(0 \cdot 5) \\
0(0 \cdot 0) \\
0(0 \cdot 0) \\
2(0 \cdot 3) \\
16(2 \cdot 0)\end{array}$ & $\begin{array}{l}1(0 \cdot 1) \\
0(0 \cdot 0) \\
1(0 \cdot 1) \\
1(0 \cdot 1) \\
0(0 \cdot 0) \\
2(0.3) \\
0(0.0) \\
0(0.0) \\
5(0.6)\end{array}$ \\
\hline
\end{tabular}

^Blind: vision less than $3 / 60$. $†$ Low vision: less than $6 / 18$ to $3 / 60$. $¥$ Other causes include measles, bush medicine, and corneal scarring.

Blindness is the most serious sequel of onchocerciasis, and the three people who were bilaterally blind (vision $<3 / 60$ in each eye) all had lesions attributable to onchocerciasis (Table 4). In addition, there were 16 people who were monocularly blind (vision $<3 / 60$ in the worst eye), and five of these were blind from onchocerciasis. Seven of those with monocular blindness had some visual impairment (vision $<6 / 18$ ) in the fellow eye. In four of these the visual impairment was due to onchocerciasis lesions. Five subjects $(0.6 \%)$ had binocular low vision and five $(0 \cdot 6 \%)$ had monocular low vision. Thus 29 subjects had visual impairment in one or both eyes. In $9(31.0 \%)$ this was attributed to onchocerciasis, and of those in whom blindness or low vision was due to onchocerciasis it was due to anterior segment disease in four $(40.0 \%)$ and to posterior segment disease in six $(60 \cdot 0 \%)$.

\section{ANTERIOR SEGMENT FINDINGS}

MfAC were present in $191(23.9 \%)$. The prevalence of microfilariae in the anterior chamber increased with age for both males and females (Fig 1). Live and dead microfilariae (MfC) were present in $13.6 \%$ of the population overall, but, except for an apparent increase in elderly women, there was less of an increase with age (Fig 2). The proportion of those with punctate corneal opacities was $19 \cdot 1 \%$ overall, with no clear age or sex dependency, but again there was an increase

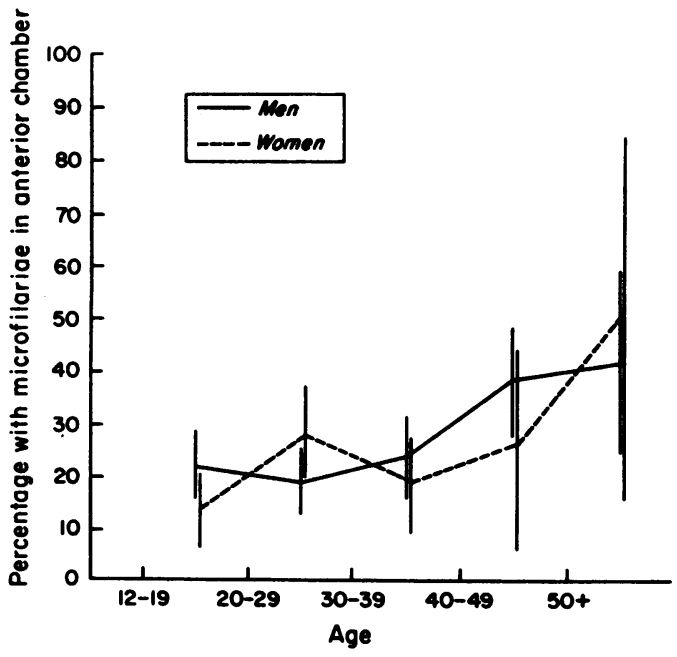

Figure 1 Proportion and 95\% confidence limits of those with microfilariae in the anterior chamber.

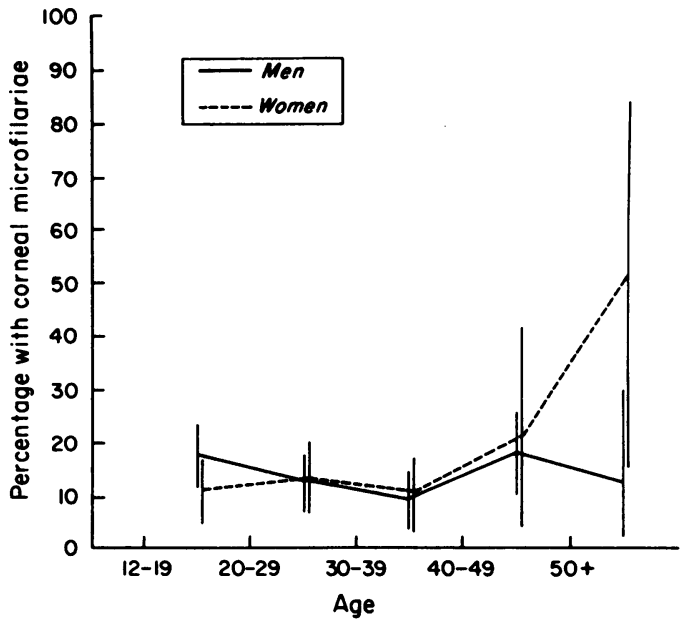

Figure 2 Proportion and $95 \%$ confidence limits of those with microfilariae in the cornea.

in prevalence in the older women (Fig 3). Sclerosing keratitis had an overall prevalence of $5 \%$ and was more common in the older subjects (Fig 4).

\section{POSTERIOR SEGMENT FINDINGS}

Chorioretinal changes were present in 596 $(76 \cdot 2 \%)$ of 782 subjects with readable fundus photographs (Fig 5-11). The commonest change was intraretinal pigment (IRP), which occurred in 405 patients $(51.8 \%)$, while retinal pigment epithelium atrophy was found in $251(32 \cdot 1 \%)$. Less common were white intraretinal deposits in $168(21.4 \%)$ and shiny intraretinal deposits in 79 $(10 \cdot 1 \%)$ of the patients (Table 5$)$. On univariate analysis atrophy of retinal pigment epithelium was correlated with age, $\mathrm{MfC}$, punctate corneal opacities, total number of nodules, MfS, sclerosing keratitis, and being a tapper. Age and MfC remained significantly correlated in multivariate analysis after controlling for other risk factors $(p<0.05)$. Subretinal fibrosis and optic neuropathy were both associated with increasing age. Subretinal fibrosis, optic neuropathy, IRP, and retinitis were all associated with uveitis, and the correlation persisted for IRP and retinitis after multivariate analysis. IRP was also found in those with MfAC and a skin rash. Retinitis was

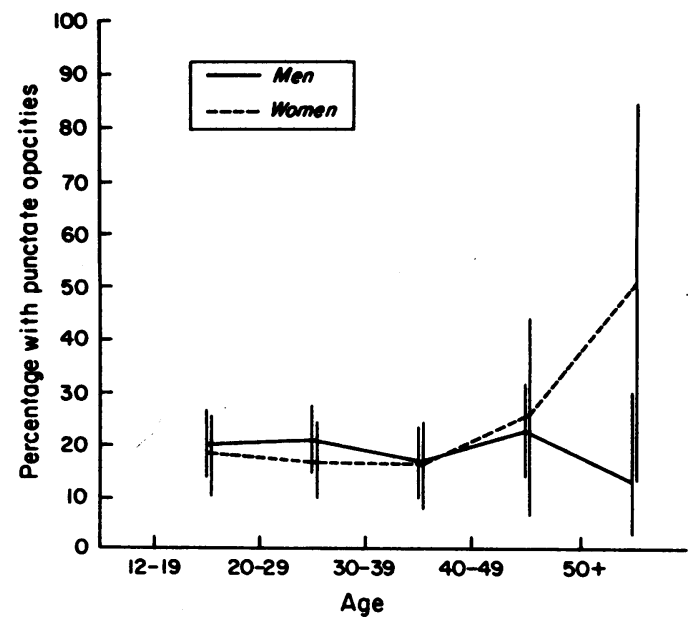

Figure 3 Proportion and 95\% confidence limits of those with punctate opacities in the cornea. 


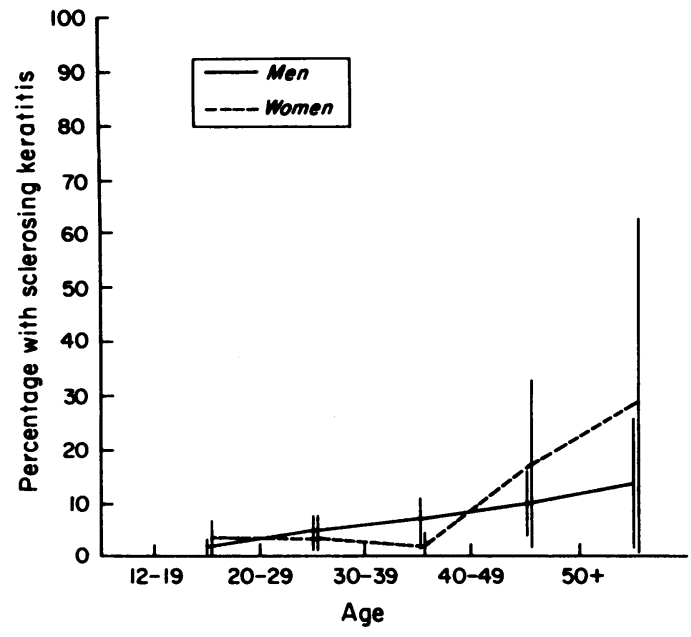

Figure 4 Proportion and 95\% confidence limits of those with sclerosing keratitis.

associated with prior treatment with diethylcarbamazine and with limbitis. White and shiny intraretinal deposits were weakly correlated with punctate opacities in the cornea.

All the people were classified on clinical and parasitological findings as to the overall likelihood of their actually having onchocerciasis. It should be remembered that they lived in an endemic area and were highly likely to have been exposed, if not infected. Those who had microfilariae in either the skin or the eye were classified as having definite onchocerciasis; those without skin or ocular microfilariae but who had punctate corneal opacities, sclerosing keratitis, charactersitic nodules, a history of previous treatment, or who had skin lesions consistent with onchodermatitis were classified as having probable onchocerciasis. People in whom all of the above criteria were negative were considered not to have onchocerciasis. Subretinal fibrosis and optic neuropathy were found only in those with definite onchocerciasis; retinitis, limbitis, and uveitis were found in those in the definite or probable groups (Table 6). Interestingly, atrophy

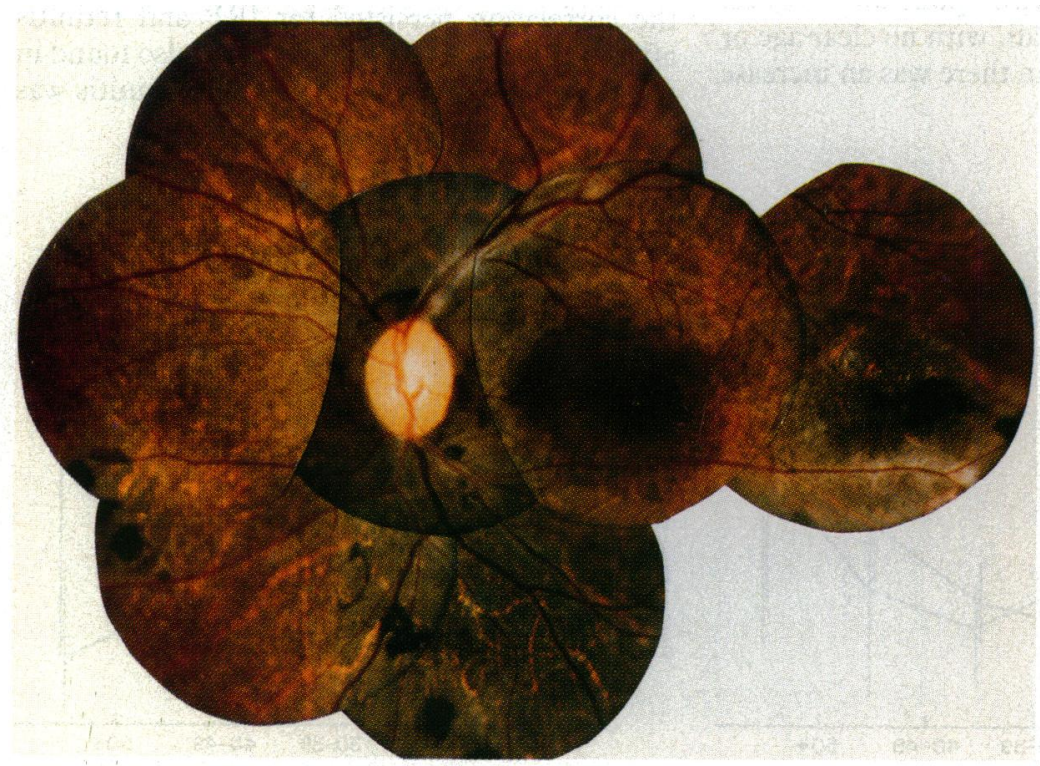

Figure 5 Montage of fundus showing discrete areas of retinal pigment epithelium atrophy (RPEA) and areas of RPE hypertrophy in a 19-year-old male with a mean skin snip count of $17 \mathrm{Mf} / \mathrm{mg}$.

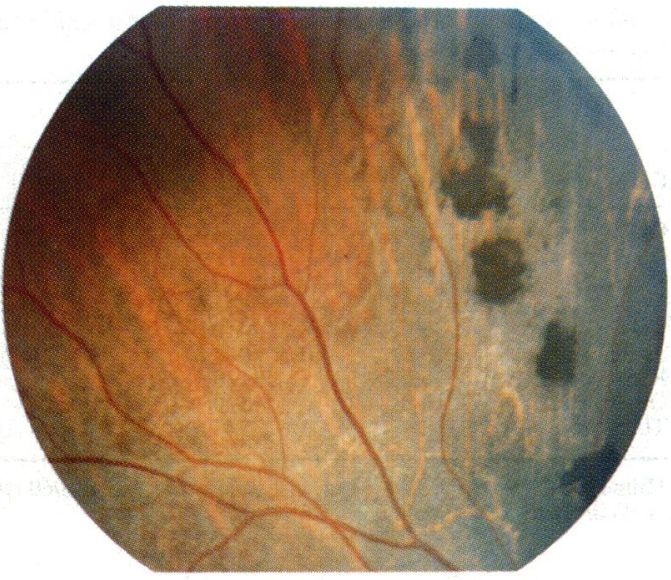

Figure 6 Severe chorioretinitis and intraretinal pigment clumping in a 19-year-old male with a mean skin snip count of $15 \mathrm{Mf} / \mathrm{mg}$.

of retinal pigment epithelium was common in each group but more prevalent in those patients with definite or probable onchocerciasis.

There was no correlation between onchocerciasis status and either age or sex, though a higher proportion of rubber tappers had onchocerciasis.

\section{Discussion}

Onchocerciasis was the main cause of bilateral blindness in this population. We found a high prevalence of ocular involvement and in particular a high prevalence of posterior segment changes. The examinations were in part carried out as a preliminary screen for clinical trial. ${ }^{131+}$ This may have introduced some bias, as it is possible that those who considered themselves healthy might see litttle purpose in participating. Indeed, we ascertained by interview that the requisite blood samples and skin biopsies were deterrents to participation for at least some people.

We found a prevalence of infection of $84 \%$. This is higher than in a previous study in the area in 1975, which reported a prevalence of infection of only $63 \%,{ }^{15}$ but they took fewer skin snips. During the past 10 years there have been important changes in this area associated with the progressive development of the plantation,

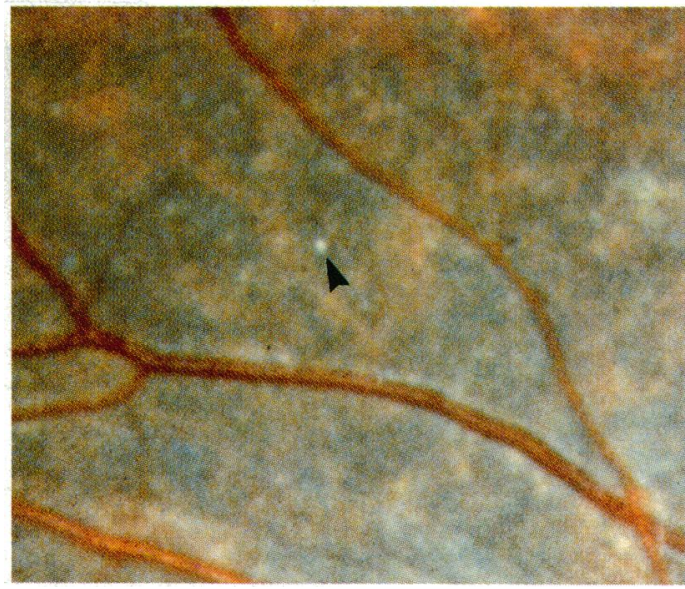

Figure 7 A shiny white deposit (arrow). 


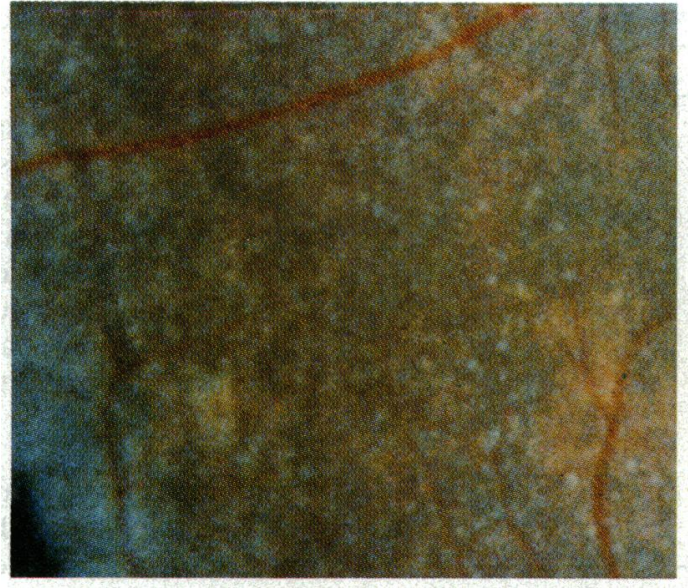

Figure 8 Multiple white intraretinal deposits temporal to the macula in a 19-year-old male with a mean skin snip count of $17 \mathrm{Mf} / \mathrm{mg}$.

which requires the recruitment of new workers, many of whom came from other hyperendemic areas.

The density of infection was especially high in males and tappers, who were also at higher risk of infection than other occupations. The tappers, who are mostly male, work among the rubber trees near the breeding sites and are more exposed to the biting black flies that transmit onchocerciasis. Their clothing, often minimal, offers little protection from the flies. It is interesting that there was not a correspondingly high proportion of blind tappers. Almost paradoxically, it was the elderly females who had the highest rate of blindness. This may be because tappers leave the plantation when their vision is so badly affected that they are no longer able to work. On the other hand the wives or female relatives of sighted male employees would remain for as long as their husbands worked, and this would artificially increase the numbers of visually impaired females.

The prevalence of bilateral blindness was also relatively low $(0.4 \%)$ but it was all attributable to onchocerciasis. This rate is still twice that of most developed countries. ${ }^{16}$ In other studies in rain forest areas, Anderson et al reported a $2 \cdot 0 \%$ blindness rate from all causes in the Cameroon rain forest, three-fourths of which was due to onchocerciasis. ${ }^{17}$ In Liberia, Frentzel-Beyme

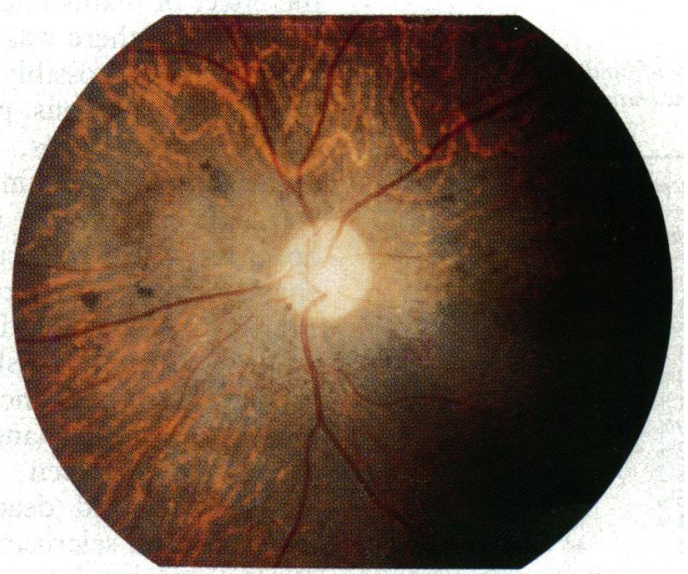

Figure 9 Advanced retinitis, IRP, RPEA, and otpic atrophy in a 30-year-old female with a mean skin snip count of $111 \mathrm{Mf} / \mathrm{mg}$.

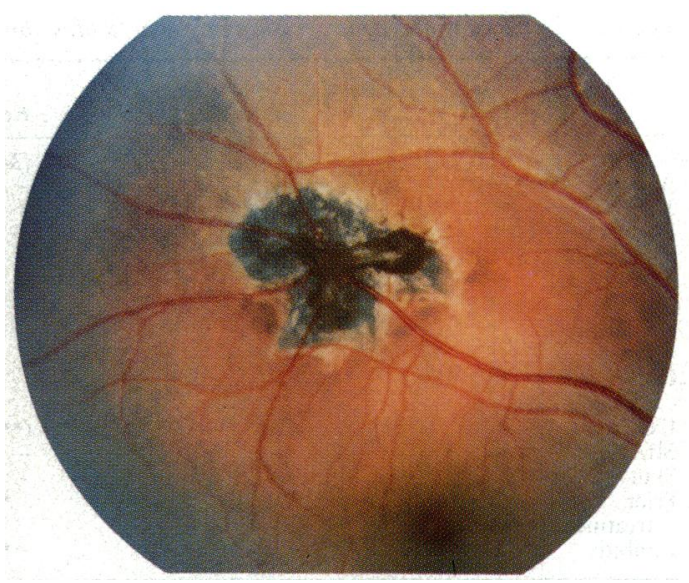

Figure 10 Area of subretinal fibrosis with overlying pigment in a 17-year-old male patient with a mean skin snip count of 6 Mflmg.

reported a $1 \cdot 2 \%$ blindness rate among 285 persons in a rural area, ${ }^{9}$ with the majority of blindness due to onchocerciasis. From a larger survey he later reported a $1.9 \%$ prevalence of blindness, with one-fourth attributable to onchocerciasis. ${ }^{18}$

The presence of microfilariae in the anterior chamber (MfAC) is often taken as a measure of ocular disease in onchocerciasis, but the validity of this as an indicator is limited by the relative difficulty in obtaining reproducible data unless the examination technique is standardised. ${ }^{19}$ Prevalence figures for MfAC from various studies in Liberia show considerable differences for the data we report. Connor and coworkers found microfilariae in the anterior chamber in about $41 \%$ of their subjects, ${ }^{10}$ while Frentzel-Beyme reported a prevalence of only $8.7 \% .^{9}$ This lower figure is almost certainly due in part to the fact that the patients were examined without previous positioning with the head down.

In the present study, as in the Cameroon rain forest, ${ }^{20}$ older women had a higher prevalence of corneal microfilariae and punctate opacities. Perhaps this is because the older women remain in the population longer, but hormonal factors have also been implicated. Anderson and coworkers suggest that a protective role is played by hormonal factors in females during their reproductive years. ${ }^{20}$

The prevalence of sclerosing keratitis was higher in our Liberian study (5\%) than the $1 \cdot 6 \%$

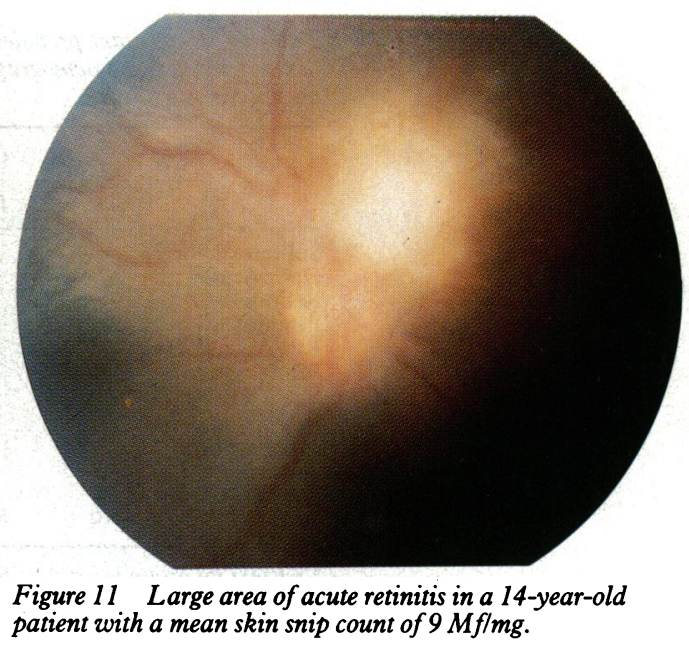


Table 5 Univariate and multivariate analysis of fundus abnormalities

\begin{tabular}{|c|c|c|c|c|c|c|c|}
\hline & RPEAt & $\begin{array}{l}\text { Subretinal } \\
\text { fibrosis }\end{array}$ & $\begin{array}{l}\text { Optic } \\
\text { neuropathy }\end{array}$ & $I R P \ddagger$ & Retinitis & $\begin{array}{l}\text { White } \\
\text { deposits }\end{array}$ & $\begin{array}{l}\text { Shiny } \\
\text { deposits }\end{array}$ \\
\hline & $(251)$ & (8) & $(8)$ & $(405)$ & (34) & (168) & (79) \\
\hline Age & $(\star \star \star)$ & $\star \star \star \star$ & $\star \star$ & - & - & - & - \\
\hline MfC & $(\star \star)$ & - & $\star$ & - & - & - & $\star \star$ \\
\hline $\begin{array}{l}\text { Punctate } \\
\text { opacities }\end{array}$ & $\star \star \prime$ & - & - & - & - & * & $\star$ \\
\hline Nodule total & $\star \star$ & - & - & - & - & $\star \star$ & - \\
\hline MfS & $\star$ & - & - & - & - & - & - \\
\hline $\begin{array}{c}\text { Sclerosing } \\
\text { keratitis }\end{array}$ & * & - & - & - & - & - & - \\
\hline $\begin{array}{l}\text { Occupation } \\
\text { tapper }\end{array}$ & $\star \star$ & - & - & - & - & - & - \\
\hline Uveitis & _- & $\star \star \star$ & $\star \star \star \star$ & $(\star \star)$ & $(\star \star)$ & - & - \\
\hline MfAC & - & - & - & $\star \star \prime$ & - & $\star$ & - \\
\hline Skin rash & - & - & - & * & - & - & - \\
\hline $\begin{array}{l}\text { Prior } \\
\text { treatment }\end{array}$ & - & - & - & - & $\star$ & - & - \\
\hline Limbitis & - & - & - & - & 夫 & - & - \\
\hline
\end{tabular}

${ }^{\star} p=0.09$ to $0.05 .{ }^{\star \star} p=0.04$ to $0.01 .{ }^{\star \star \star} p<0.01$. ( ) Significant after multivariate analysis, controlling for other risk factors. + Retinal pigment epithelium atrophy. $\neq$ Intraretinal pigment.

$\$$ Numbers in parentheses are numbers of people with fundus abnormality in one or both eyes.

prevalence found in the Cameroon rain forest. ${ }^{20}$ Although the early stage of limbal haze was not classified as sclerosing keratitis in the Cameroon study, when Liberian subjects with limbal haze alone were excluded the overall prevalence still remained at $4 \cdot 2 \%$. Sclerosing keratitis was often seen in a milder form in the Liberian rain forest population than in the savanna, and in this population of largely able-bodied men it was associated with relatively little visual impairment. It was the cause of bilateral blindness in one patient, while secondary glaucoma caused blindness in another.

The advanced chorioretinal abnormalities associated with onchocerciasis have been described in detail, ${ }^{21}$ but little is known about the earlier stages of ocular involvement. A high number of vitreoretinal changes were reported in a study of 30 Liberian men " who were examined in great detail with direct and indirect ophthalmoscopy, fundus photography, fluorescein angiography, and triple-mirror contact lens examination. Even in the present study, with a somewhat less detailed examination including only indirect ophthalmoscopy and fundus photography, the prevalence of chorioretinal changes was high.

The pathogenesis of the chorioretinal changes in onchocerciasis is not clear, and many theories have been advanced. In 1935 Bryant suggested that the adult worms secrete a systemic toxin which affects the fundus and optic nerve. ${ }^{22}$ This

Table 6 Percentage prevalence of fundus abnormalities, ocular findings, and demographic characteristics by onchocerciasis status

\begin{tabular}{lcccc}
\hline & \multirow{4}{c}{$\begin{array}{c}\text { Total } \\
\text { number }\end{array}$} & \multicolumn{3}{c}{ Onchocerciasis status } \\
\cline { 2 - 5 } & Definite & Probable & None \\
\hline Subretinal fibrosis & 8 & $1 \%$ & 0 & 0 \\
Optic neuropathy & 7 & $1 \%$ & 0 & 0 \\
Retinitis & 34 & $5 \%$ & $5 \%$ & 0 \\
Limbitis/uveitis & 20 & $3 \%$ & $2 \%$ & 0 \\
RPEA & 248 & $34 \%$ & $32 \%$ & $22 \%$ \\
White deposits & 158 & $21 \%$ & $20 \%$ & $22 \%$ \\
Shiny deposits & 75 & $9 \%$ & $18 \%$ & $10 \%$ \\
IRP & 395 & $52 \%$ & $52 \%$ & $53 \%$ \\
Mean age (years) & & $28 \cdot 2$ & $28 \cdot 7$ & 24.1 \\
Males & & $66 \%$ & $66 \%$ & $59 \%$ \\
Rubber tapperst & $756 \ddagger$ & $64 \%$ & $9 \%$ & $3 \%$ \\
Total & $71 \%$ & 44 & 71 \\
\hline
\end{tabular}

* See text for grounds for classification. $¥$ Twenty four people had missing MfS values and 20 had unreadable photographs. $f \chi^{2}$ test,
$p=0.001$. type of process would be consistent with the bilateral symmetrical nature of the disease. Bryant also suggested that microfilariae invade the optic tract producing perivascular infiltration and bilateral symptoms.

In 1945 Ridley concluded from his own, and other, observations that dead microfilariae in the choroid cause occlusion of the smaller blood vessels and atrophy of the retina. ${ }^{23} \mathrm{He}$ also implicated perivascular infiltration and endothelial proliferation of the short ciliary vessels in the production of a diffuse choroidoretinal degeneration. In 1955 Budden echoed Bryant's suggestion that posterior segment damage might be due to the effects of toxins released by adult worms. ${ }^{24} \mathrm{~A}$ combined effect of these toxins and avitaminosis A was postulated by Rodger, ${ }^{25}$ whereas Choyce suggested that onchocercal chorioretinitis was only a genetic condition. ${ }^{26}$ Neumann and Gunders suggested that the chorioretinal lesion was either due to an inflammatory reaction caused by the death of microfilariae in situ in the posterior segment or diffusion of toxic products from disintegrating microfilariae into the choroid and retina. ${ }^{27}$ Garner suggested that the marked retinal and choriocapillaris atrophy was attributable to a preceding choroiditis. ${ }^{28}$

Although the precise mechanism is unknown, the role of systemic immune processes in pathogenesis of some of the complications of onchocerciasis has been established. ${ }^{29-31}$ An association between circulating immune complexes and the occurrence of major ocular complications, including chorioretinitis, was reported. ${ }^{32}$ Furthermore, circulating antibodies against various retinal antigens, including retinal $S$ antigen have been demonstrated in patients with retinopathy due to onchocerciasis. ${ }^{33-35}$

Donnelly and coworkers have demonstrated that chorioretinal changes similar to those in the human onchocerciasis occur in a monkey model after the vitreal injection of $O$ volvulus microfilariae. ${ }^{36}$ They suggested that the changes could be directly related to the presence of microfilariae in the retina. Microfilariae were found in the retina adjacent to the areas of retinal pigment epithelial changes, but with no surrounding inflammation. This would point to either a purely mechanical effect resulting from the passage of microfilariae through the retina or to the effect of toxins released by microfilariae. In their studies there was massive death of microfilariae and possibly an accumulation of microfilarial antigens, producing a change in the host immune status. This in turn could be followed by severe inflammation causing the tissue damage in the retina. Punctate corneal opacities, which are acute inflammatory foci enveloping dead microfilariae, demonstrate a similar chain of events in the anterior segment.

We conducted a risk factor analysis to gain further insight into the pathogenesis of some of the chorioretinal changes. We found a strong correlation between both anterior segment disease (live and dead microfilariae punctate opacities, and sclerosing keratitis) and systemic markers of cumulative disease (age, numbers of skin microfilariae, occupation, and total number of nodules). This suggests that similar 
mechanisms are likely to cause both atrophy of retinal pigment epithelium and the anterior segment changes. The significance of the shiny, white intraretinal deposits seen in patients with onchocerciasis in unclear. These lesions were correlated with punctate opacities and may point to an inflammatory aetiology. It is possible that they represent the retinal equivalent of the corneal lesions and are small focal areas of inflammation surrounding dead or dying microfilariae; it may not be possible to determine their exact nature until further histopathological material is available.

The impact of onchocerciasis in rain forest areas in terms of visual impairment has often been underestimated, but our results suggest it is of considerable importance. Most posterior segment changes in onchocerciasis threaten sight and may cause irreversible damage. Further studies are needed to identify risk factors for chorioretinitis in hyperendemic areas and to treat as early as possible so that some visual loss may be prevented.

We are grateful to the following persons for their support and assistance: Dr P Noel William, Mr Ken Gerhart, and their staff of the Liberian Agriculture Company; Mrs Theo Greene, Case Western Reserve University and University Hospitals of Cleveland; and Dr E Keyvan-Larijani, Mr Sam D'Anna and Mrs Inga Jackman, Johns Hopkins University

This study was supported in part by the Onchocerciasis Chemotherapy Project of the FAO/UNDP/World Bank/WHO Onchocerciasis Control Programme in the Volta River Basin Area.

1 Prost A. The burden of blindness in adult males in the savannah villages of West Africa exposed to onchocerciasis. Trans $R$ Soc Trop Med Hyg 1986; 80: 525-7.

2 Prost A, Vaugelade J. La surmortailité des aveugles en zone de savane Ouest-Africaine. Bull WHO 1981; 59:773-6.

3 Anderson J, Fait RL. Ocular onchocerciasis. In: Bulford CH, Connor DH, eds. Pathology of tropical and extraordinary diseases. Washington: Armed Forces Institute of Parasitology, 1976; 373-81.

4 Anderson J, Fuglsang H. Ocular onchocerciasis. Tropical Diseases Bulletin 1977; 74: 257-72.

5 Strong RP. The African Republic of Liberia and the Belgian Congo. Boston: Harvard University Press, 1930.

6 Burch TA, Qualls DM, Greenville HJ. Onchcerciasis in Liberia. Am 7 Trop Med Hyg 1955; 4: 923-9.
Liber.

7 Miller MJ, Franz KN. Some clinical aspects of onchocerciasis in Liberia. Am F Trop Med Hyg 1958; 7: 558-60.

8 Miller MJ, Gunders AE. Studies on onchocerciasis in Liberia. Proceedings of the Smith International Congress of Tropical Medicine and Malaria. Instituto de Medecina Tropical, Lisbon, 1958 .

9 Frentzel-Beyme R. The prevalence of onchocerciasis and blindness in the population of the Bong Range, Liberia. Trop Med Parasitol 1973; 24: 339-57.

10 Connor DH, Cupp EW, Ganley JP, Gibson DW, Schiller EL. Report of studies on onchocerciasis in Northern Liberia, including topical treatment with diethylcarbamazine: pathology, ophthalmology, parasitology, and entomology; and recommendation for mology, parasitology, and entomology; and recommendation for
control of the disease. American Public Health Association: control of 1978.

11 Taylor HR, Murphy RP, Newland HS, et al. Treatment of onchocerciasis; the ocular effects of ivermectin and diethylcarbamazine. Arch Ophthalmol 1986; 104: 863-70.
12 Diabetic Retinopathy Study Research Group. Report No. 6: Design, methods, and baseline results. Invest Ophthalmol Design, methods, and

13 White AT, Newland HS, Taylor HR, et al. Controlled trial and dose-finding study of ivermectin for treatment of onchocerciasis. F Infect Dis 1987; 156: 463-70.

14 Newland HS, White AT, Greene BM, et al. The effect of single dose ivermectin therapy on human Onchocerca volvulus infection and onchocercal ocular involvement. Brf Ophthalmol 1988; 72: 561-9.

15 Frentzel-Beyme R. The geographical distribution of $O$ volvulus infection in Liberia. Trop Med Parasitol 1975; 26: 70-87.

16 World Health Organisation. Methods of assessment of avoidable blindness. WHO Offset Publication No. 54. Geneva: World Health Organisation, 1980

17 Anderson J, Fuglsang H, Hamilton PJS, Marshall TFdeC. Studies on onchocerciasis in the United Cameroon Republic Studies on onchocerciasis in the United Cameroon Republic II. Comparison of onchocerciasis in rain-forest and Sudan-
Savannah. Trans $R$ Soc Trop Med Hyg 1974; 68: 209-21.

18 Frentzel-Beyme RR. Visual impairment and incidence of blindness in Liberia and their relation to onchocerciasis. Trop Med Parasitol 1975; 26: 469-88.

19 Thylefors B, Brinkmann UK. The microfilarial load in the anterior segment of the eye. A parameter of intensity of onchocerciasis. Bull WHO 1977; 55: 731-7.

20 Anderson J, Fuglsang H, Hamilton PJS, Marshall TFdeC. Studies on onchocerciasis in the United Cameroon Republic I. Comparison of populations with and without Onchocerca volvulus. Trans $R$ Soc Trop Med Hyg 1974; 68: 190-208.

21 Bird AC, Anderson J, Fuglsang H. Morphology of posterior segment lesions of the eye in patients with onchocerciasis. $\mathrm{Br}$ segment lesions of the eye in pati

22 Bryant J. Endemic retino-choroiditis in the Anglo-Egyptian and its possible relationship to Onchocerca volvulus. Trans $R$ Soc Trop Med Hyg 1935; 28: 523-32.

23 Ridley $\mathrm{H}$. Ocular onchocerciasis, including an investigation in the Gold Coast. Br f Ophthalmol 1945; suppl 10

24 Budden FH. Incidence of human infection with onchocerciasis in different communities in relation to the incidence and type of the ocular lesions. Brf Ophthalmol 1955; 39: 321-32.

25 Rodger FC. Posterior degenerative lesion of onchocerciasis. $\mathrm{Br}$ F Ophthalmol 1958; 42: 21 .

26 Choyce DP. IV. Some observations on the ocular complications of onchocerciasis and their relationship to blindness. Trans $R$ Soc Trop Med Hyg 1958; 52: 112-21.

27 Neumann E, Gunders AE. The posterior segment lesion of ocular onchocerciasis. Histological aspects. Isr $\mathcal{f}$ Med Sci 1972; 8: 8-9.

28 Garner A. Pathology of ocular onchocerciasis: human and experimental. Trans R Soc Trop Med Hyg 1976; 70: 374-7.

29 Greene BM, Taylor HR, Humphrey RL. Proteinuria associated with diethylcarbamazine treatment of onchocerciasis. Lancet 1980; i: $254-5$.

30 Paghandi R, Ngu JL, Levinsky RJ. Circulating immune complexes in onchocerciasis. Clin Exp Immunol 1980; 39: $570-5$.

31 Steward MW, Sisley B, Mackenzie CD, El Sheikh H. Circulating antigen-antibody complexes in onchocerciasis. Clin Exp Immunol 1982; 48: 17-24.

32 Greene BM, Taylor HR, Brown EJ, Humphrey RL, Lawley TJ. Ocular and systemic complications of diethylcarbamazine therapy for onchocerciasis: association with circulating immune complexes. F Infect Dis 1983; 147: 8907.

33 Newsome DA, Hewitt TA, Quinn TC, et al. Immune status alteration in onchocerciasis, with and without retinopathy. $X X V$ International Congress of Ophthalmology. 1986: 4

34 Vintain P, Thillaye B, LeHoang P, Sanite-Landy J, Chanderver J, Faure JP. Sensitivity of patients with ocular onchocerciasis to filarial antigen and retinal autoantigen. Fourth International Symposium on Immunology and Immunopathology of the Eye 1986: 51 .

35 Chan C, Nussenblatt RB, Kim MY, Palestine AG, Awadzi K, Ottesen EA. Immunopathology of ocular onchocerciasis 2: Ophthalmology 1987; 94: 439-43.

36 Donnelly JJ, Taylor HR, Khatami M, et al. Immunopathology of onchocerciasis: ocular disease in monkeys. Invest Ophhalmol Vis Sci 1984; 25 (suppl): 188-4. 